\title{
Review of Maggi Savin-Baden (Ed.). (2021). Postdigital Humans: Transitions, Transformations and Transcendence
}

\section{Cham: Springer. 209 pp. ISBN 9783030655914 (Hardcover)}

\section{Mark Carrigan ${ }^{1}$}

Accepted: 20 July 2021/ Published online: 7 August 2021

(c) The Author(s), under exclusive licence to Springer Nature Switzerland AG 2021

\section{Beyond the Shock of the New}

What does it mean to be human? If this question could once have been assumed to have a stable answer, this is no longer the case. Artificial intelligence, synthetic biology and cognitive enhancement are just a few categories of emerging technologies which are widely regarded as inviting a reappraisal of the core category of the human being. There are multiple reasons for this which often overlap in how this perceived challenge is explained, such as a transformation of human biological characteristics, a radical increase in psychophysical inequalities between humans or mundane dependence upon non-biological intelligences. In spite of the conceptually messy character of this field, there is an emerging consensus within both scientific and popular debates that there is a challenge which needs to be addressed. It should be noted this is not a new project, with a clear genealogy linking the anti-humanism of twentieth century continental philosophy and the posthumanism which occupies a roughly homologous position within contemporary social thought. However, there is something new about the vigour with which this project is being pursued, motivated in part by the ubiquity of once fantastical devices as newly mundane features of our social life.

Postdigital Humans: Transitions, Transformations and Transcendence (SavinBaden 2021) is a welcome contribution to this debate, with the potential to speak to these discussions while also moving them forward through the introduction of the postdigital alongside the more familiar framings of posthumanism and transhumanism. Postdigital thought sets itself in opposition to the determinism and hyperbole which characterised treatments of the digital in the late twentieth and early twentyfirst century, instead proceeding from 'contemporary disenchantment with digital information systems and media gadgets' and the recognition that 'our fascination

Mark Carrigan

mark@markcarrigan.net

1 University of Cambridge, Cambridge, UK 
with these systems and gadgets has become historical' (Cramer 2015: 12). In doing so, it helps us move beyond the 'shock of the new' which has so often pervaded posthumanist thought (and one could argue is perhaps a defining feature of transhumanist thought) in the sense of decentring emerging technologies without dismissing them. It helps us move beyond a facile dichotomy in which the stubborn refusal of change is counterpoised to the breathless innovation of transformation.

In this sense, the framing of the postdigital has the potential to contribute to a more nuanced approach across overlapping literatures which too often remain stuck at the level of epochal pronouncements (Carrigan and Porpora 2021). It is an invitation to consider the mundane entanglements and blurred boundaries which characterise the sometimes feral circulation of emerging technologies, as can be seen for example in the rapid growth of cognitive enhancers facilitated by online shadow commerce or the parasocial relationships with hosts which have come to characterise podcasting culture during the pandemic. It is clear there is much to be said about the category of the human from a postdigital perspective, with the tribulations of the COVID-19 pandemic lending an urgent feel to this endeavour given the central role technology has played in this all too human crisis.

\section{Who Are Postdigital Humans?}

The most straightforward answer to this question comes from Jandrić (2021: 21) who suggests 'the postdigital human is a human being living in the postdigital condition defined by vanishing borders between the digital and the analog in all spheres of life, including their own body'. To leave matters there though would be misleading, as it would fail to recognise the range of phenomena which are caught up within the terms of this broad definition. Savin-Baden (2021: 11) observes early on that 'the term postdigital human is used in wide ranging ways to cover anything from virtual humans to surveillance practice'. This points to a degree of overlap between postdigital and posthuman thought, in the sense that it is oriented towards nonhuman actors who should nonetheless receive the recognition which enlightenment thought has tended to restrict to the category of the human.

As well as the aforementioned intersection between humans and the postdigital, best understood as those "entangled in different configurations of human-machine assemblages' to use Jandrić's (2021: 20) definition, there are also other biological and non-biological entities which are possible candidates for postdigital humans. This points forwards towards the horizon and the real possibility that 'some postdigital humans may look and feel radically different from Homo Sapiens' (Jandrić 2021: 25). To talk of postdigital humans might begin with Homo Sapiens but it certainly doesn't end with them.

The greatest strength of Postdigital Humans is the variety of the collection. It's made up of three sections, 'Conceptions of Postdigital Humans', 'Postdigital Humans and Education and Philosophy', 'Ethics and Religion', which between them contain eleven chapters. There's a curiously backloaded character to the volume, with two chapters in the first section, four in the second section and five in the third section. This might have been a quirk of the editorial process but in an odd way 
I found this an immensely readable feature of the book. It left a sense of a panorama opening out as the volume progressed, with an eclectic mix of conceptual and empirical inquiry across the broad theme of each section.

This collection brings a remarkable range of topics into dialogue with each other, using postdigital humans as a nexus point to link them together. These encompass topics like virtual life coaching, the educational implications of fake news, the politics of listening and the dehumanisation of higher education. The diversity of the chapters extends to methodology as well as topic, reflecting the transdisciplinary research community of postdigital scholars and the multiple forms of inquiry found within it. I thought it was particularly admirable that this diversity did not come at the cost of coherence, with Postdigital Humans feeling like a singular project in spite of the sheer range of components which constitute it. However, I felt the volume was less effective at unpicking and explaining the relationships between these varied topics for a number of reasons which I think are interesting to explore.

\section{Posthumanism and Transhumanism}

There's a blurring of boundaries between postdigital humans, posthumanism and transhumanism which cuts through the volume. Thomas (2021) is a welcome exception to this with a clear delineation between posthumanism and transhumanism, recognising a faith in human reason and the possibility of uplift as a crucial faultline between them. As he observes, '[c]ritical posthumanists tend to reject hierarchical conceptualisations, eschewing the idea of humans at the apex of Earthly species, bringing into question the very concept of "uplift" and "enhancement" that is so vital to the transhumanist critique' (Thomas 2021: 170).

Furthermore, Brown's chapter on the moral formation of posthumans included thoughtful analysis of the human which is being acted upon by the qualifiers 'post', 'trans' and 'postdigital'. He memorably points to the 'moist and messy reality of being human' which reinforces the 'shared creatureliness' which unites us with nonhuman animals, as well as the ambiguous connections between 'the cerebral and the visceral' which simultaneously sets us apart from them (Brown 2021: 126). Beyond this, there's little engagement with transhumanism which was surprising given the transhumanist themes which pervade some of the chapters, as well as the presence of a leading transhumanist thinker amongst the authors. In contrast, posthumanism figures much more prominently but is often used as if talk of posthumans is (roughly) synonymous with postdigital humans.

To point this out isn't to disagree with it but rather to express surprise that it seems to have been assumed rather than argued for. It raises the obvious question of what the prefix postdigital contributes to these debates if there is equivalence between the terms. It seems clear that postdigital scholarship has much to contribute to these debates and Postdigital Humans demonstrates this substantively in spite of the ambiguous way in which some of these terms are put into relation with each other.

This isn't a trivial point about a lack of specificity with terminology but rather a suggestion that the two traditions of posthumanism and transhumanism must be 
understood in tension with each other, as conflicting responses to the socio-technical environment which we are now entering into. If we subsume them both under a general sense of the human changing, then we obscure the range of theoretical and political possibilities opened up by those changes. There is a space of philosophical, sociological and political questions which posthuman and transhuman thought are responding to in different ways, reflecting contrasting impulses to deconstruct or transcend the category of the human. To distinguish between them more clearly would help illustrate what postdigital thought brings to the problems which these thinkers are grappling with. Is it just another way of talking about posthumans? Or does it provide us with analytical techniques and strategies which can help circumvent some of the roadblocks found within at times repetitive and nebulous literatures?

Postdigital Humans persuaded me the answer is certainly the latter but to fully realise this promise postdigital thought requires a more theoretically systematic debate with posthumanism and transhumanism. In its absence, there's a risk postdigital engagements with the question of the human might slide into an avant-garde valorisation of the new as interesting (if not necessarily desirable) which would not be in keeping with the postdigital approach.

\section{Postdigital Humans and Their Politics}

It follows from this that there is a tension concerning the status of the human which cuts through the volume without ever really being systematically explored. To a certain extent, this is an inevitable reflection of the diversity of the contributions and the thriving research community from which they were drawn. It reflects the admirably heterodox character of postdigital thought that these positions can fall so naturally into dialogue with others. There's nonetheless an ambivalence about the human in this volume which invites further analytical inquiry, even if normative resolution is undesirable. Should we welcome the emergence of postdigital humans? I was struck by the phrase used by Savin-Baden in the introduction describing the "marketised diminishment of the human' (2021: xv) which results from the operations of contemporary capitalism. I share this analysis and I believe this is a philosophically and politically useful way to make the point, i.e. we lose something of what makes us human when we come to be bound up within digital platforms which reduce us to our digital traces (Carrigan 2018). It was well put by Hall (2021: 55) who talks about the postdigital human as manufactured through the operations of economic power.

This opens up a sense of the postdigital human as something regrettable and avoidable, representing a loss of solidaristic horizons as educators come to be tied up in the atomising machinery of digital education. The point Hall (2021: 62) later raises that the postdigital has the "potential to act as a dystopian pivot for the convergence of the personal/the person and a range of technologies' needs to be taken seriously. However, someone like Fuller (2021) has little time for the suggestion that we ought to guard our humanity against dehumanising influences. I disagree with this view but I respect it which is why I would have enjoyed seeing more unpacking of the normative 
significance of the category of the human. For some authors, it was clear that the 'human' provided a vantage point from which unwelcome developments could be regarded at a critical distance, whereas for others, the partial dissolution of the human into the postdigital human was something to be celebrated.

This preoccupation with the category of the human might seem like a narrowly philosophical question but I suggest it has immense philosophical and political significance. Brown (2021) insightfully observes how these assumptions shape technological development rather than merely responding to them, developed by moral agents who ought to be responsible vis-a-vis their creation, even if the politico-economic context and the desiccated state of technological ethics tends to militate against this. In doing so, he suggests a postdigital approach which is a deliberate intervention in order to shape socio-technical developments as well as responding to them.

This political outlook was most pronounced in Hall (2021) but it was a constant tacit presence in the volume, albeit one which would mean different things to different authors. In this way, surfacing the tensions surrounding the human would also be a means to explore the politics of postdigital humans. The timeliness of such an undertaking is attested to by the varied insights about the COVID-19 pandemic which litter the volume. Postdigital Humans: Transitions, Transformations and Transcendence (Savin-Baden 2021) is an immensely thought-provoking contribution to urgent debates which through its own heterodox and eclectic character immediately calls for a sequel. It feels like the start of a project rather than the ending of one.

\section{References}

Brown, M. (2021). Ethics, Character, and Community: Moral Formation and Modelling the Human. In M. Savin-Baden (Ed.), Postdigital Humans: Transitions, Transformations and Transcendence (pp. 125140). Cham: Springer. https://doi.org/10.1007/978-3-030-65592-1_8.

Carrigan, M. (2018). The evisceration of the human under digital capitalism. In I. Al-Amoudi \& J. Morgan (Eds.), Realist Responses to Post-Human Society: Ex Machina (pp. 165-81). London and New York: Routledge. https://doi.org/10.4324/9781351233705-7.

Carrigan, M., \& Porpora, D. V. (2021). Post-Human Futures: Human Enhancement, Artificial Intelligence and Social Theory. London and New York: Routledge.

Cramer, F. (2015). What is 'post-digital'? In D. M. Berry \& M. Dieter (Eds.), Postdigital aesthetics: Art, computation and design (pp. 12-26). New York: Palgrave Macmillan. https://doi.org/10.1057/9781137437204_2.

Fuller, S. (2021). The Computer's Hidden Theology and Its Prospects for a Postdigital Humanity. In M. Savin-Baden (Ed.), Postdigital Humans: Transitions, Transformations and Transcendence (pp. 141154). Cham: Springer. https://doi.org/10.1007/978-3-030-65592-1_9.

Hall, R. (2021). Venturing Beyond the Imposition of a Postdigital, Anti-human Higher Education. In M. Savin-Baden (Ed.), Postdigital Humans: Transitions, Transformations and Transcendence (pp. 53-70). Cham: Springer. https://doi.org/10.1007/978-3-030-65592-1_4.

Jandrić, P. (2021). Postdigital Humans: Taking Evolution in Own Hands. In M. Savin-Baden (Ed.), Postdigital Humans: Transitions, Transformations and Transcendence (pp. 17-31). Cham: Springer. https://doi. org/10.1007/978-3-030-65592-1_2.

Savin-Baden, M. (Ed.). (2021). Postdigital Humans: Transitions, Transformations and Transcendence. Cham: Springer.

Thomas, A. (2021). Transcendent Conformity: The Question of Agency for Postdigital Humans. In M. Savin-Baden (Ed.), Postdigital Humans: Transitions, Transformations and Transcendence (pp. 169185). Cham: Springer. https://doi.org/10.1007/978-3-030-65592-1_11. 